\title{
Correction to: Migration and transformation of different phosphorus forms in rainfall runoff in bioretention system
}

\author{
Yujia Song $^{1} \cdot$ Shoufa Song ${ }^{2}$ \\ Published online: 7 January 2019 \\ (C) Springer-Verlag GmbH Germany, part of Springer Nature 2019
}

\section{Correction to: Environmental Science and Pollution Research} https://doi.org/10.1007/s11356-018-2405-4

The corresponding Author of this paper transferred to another institution.

The correct affiliation is shown in this paper.

Publisher's Note Springer Nature remains neutral with regard to jurisdictional claims in published maps and institutional affiliations.

The online version of the original article can be found at https://doi.org/ $10.1007 / \mathrm{s} 11356-018-2405-4$

Yujia Song

jlsongyujia@126.com

1 College of Tourism and Geographic Sciences, Jilin Normal University, Siping, People's Republic of China

2 Northeast Coal Industry institute of Environmental Protection, Changchun, People's Republic of China 